\title{
EVALUASI PROGRAM SANITASI TOTAL BERBASIS MASYARAKAT DI KABUPATEN MAMUJU
}

\author{
Agus Erwin Ashari, Fajar Akbar \\ Jurusan Kesehatan Lingkungan Poltekkes Kemenkes Mamuju,
}

\begin{abstract}
Low coverage of family latrines, village implement community-based total sanitation (STBM) and the village of defecation Random Stop (Stop Babs) resulted in increased cases of disease based environment. The purpose of this study was to determine the components of the input, process and output for the low coverage STBM program. This study is an evaluation using a qualitative approach in 10 selected health centers in Mamuju conducted by purposive sampling based health centers category in June - August 2015. The informants are holders STBM program health centers, community health centers and the head of environmental health section chief. In collecting the data, researchers used the method triagulasi ie depth interviews, observation and document analysis. Analyses were performed with a qualitative analysis of the various opinions that combined the results of triangulation. The results showed there were several indicators of input components of adequate policies, authority and responsibility, human resources; except for operational funds and infrastructure. Kompenen planning process, pengoorganisasian and reporting is adequate, but the implementation and monitoring indicators was inadequate. Output components are all yet to reach the standards set. Conclusion there are some indicators that are not sufficient operating funds, infrastructure, implementation, and monitoring.
\end{abstract}

Keyword: evaluation, input, process, output, STBM.

\section{PENDAHULUAN}

Upaya kesehatan wajib puskesmas adalah upaya yang ditetapkan berdasarkan komitmen nasional, regional dan global serta yang mempunyai daya ungkit tinggi untuk peningkatan derajat kesehatan masyarakat. Upaya kesehatan wajib ini harus diselenggarakan oleh setiap puskesmas yang ada di wilayah Indonesia. Upaya STBM di puskesmas mencakup kegiatan penyehatan air, hygiene dan sanitasi makanan dan minuman penyehatan tempat pembuangan sampah dan limbah, STBM pemukiman dan jamban keluarga pengawasan sanitasi tempat-tempat umum dan industri, pengamanan tempat pengelolaan pestisida, klinik sanitasi puskesmas dan pengendalian vektor.

Indikator upaya STBM pada tahun 2014 antara lain persentase penduduk yang memiliki akses terhadap air minum berkualitas sebesar $67 \%$, persentase kualitas air minum yang memenuhi syarat kesehatan $100 \%$, persentase penduduk yang menggunakan jamban sehat sebanyak $75 \%$ dan cakupan rumah yang memenuhi syarat kesehatan sebanyak 85\% (Depkes RI, 2014). Cakupan kegiatan program STBM antara lain, akses sanitasi layak (jamban sehat) sebanyak 36,8\%, jumlah desa yang melaksanakan STBM sebanyak 100 desa $(28,25 \%)$ dan desa Stop BABS sebanyak 42 desa (11\%) (Dinkes Provinsi Sulbar, 2013). Penduduk dengan akses sanitasi layak (jamban sehat) sebanyak 169.562 orang $(50,30 \%)$. Jumlah desa STBM sebanyak 62 desa (40\%) dan desa Stop BABs sebanyak 4 desa (2,58\%) (Dinkes Kabupaten Mamuju, 2013). Rumah tangga yang memiliki akses ke fasilitas sanitasi juga meningkat dari 40,3\% (2007) menjadi 59,8\% (2013), pada tahun yang sama di Sulawesi Barat sebanyak 42,9\% dan Kabupaten Mamuju tercatat akses ke fasilitas sanitasi baru mencapai 44,8\% (Hadisaputro, Soeharyo, 2011).

Dalam menilai keberhasilan suatu program maka perlu dilakukan evaluasi program. Evaluasi adalah suatu upaya pengawasan dalam rangka menilai keberhasilan performance dan efektivitas program kerja sebuah institusi dalam rangka pencapaian tujuan organisasi (Arikunto, 2010). Evaluasi program adalah sebuah proses yang menentukan hasil yang telah dicapai beberapa kegiatan yang direncanakan untuk mendukung tujuan (Suharto E, Marjuki, Soeharto I, 2006). Tujuan dari penelitian ini adalah untuk mengetahui gambaran pelaksanaan input, proses dan output pada program STBM di Kabupaten Mamuju Tahun 2015. 


\section{METODE PENELITIAN \\ Jenis Penelitian}

Penelitian ini adalah penelitian evaluasi dengan pendekatan kualitatif. Variabel penelitian yaitu input program meliputi kebijakan, pembiayaan, sumber daya manusia (SDM), pedoman/ petunjuk teknis, kewenangan dan tanggung jawab.

Proses program meliputi perencanaan, pengoorganisasian, pelaksanaan dan monitoring. Output program STBM meliputi cakupan jamban keluarga, desa yang melaksanakan STBM dan desa Stop BABs.

\section{Lokasi dan Waktu Penelitian}

Penelitian ini dilakukan di Kabupaten Mamuju Provinsi Sulawesi Barat pada 10 puskesmas terpilih yang dilakukan secara purposive sampling berdasarkan kategori puskesmas yaitu puskesmas perkotaan dan pedesaan. Penelitian ini dilaksanakan pada bulan Juni - Agustus 2015.

\section{Informan Penelitian}

Informan dalam penelitian ini adalah pemegang progam STBM puskesmas, Kepala Puskesmas dan Kepala Seksi Penyehatan Lingkungan.

\section{Pengumpulan dan Analisis Data}

Dalam pengumpulan data, peneliti menggunakan data primer dan data sekunder. Data Primer diperoleh dari wawancara mendalam dengan informan dan data sekunder diperoleh dari laporan kegiatan puskesmas, laporan SP2TP dari Puskesmas.

Didalam penelitian ini juga dilakukan triangulasi yaitu triangulasi sumber (wawancara dan laporan) dan triangulasi data (pelaksana program, kepala puskesmas dan kepala seksi penyehatan lingkungan).

\section{HASIL PENELITIAN}

\section{Input Program STBM}

Input program STBM yang terdapat di tingkat puskesmas dapat dilihat dalam beberapa indikator.

\section{Sumber Daya Manusia}

Sumber daya manusia pada pengelola program kesehatan lingkungan puskesmas dilihat dari kualifikasi pendidikan dan keikutsertaan dalam pelatihan. Hasil penelitian didapatkan bahwa kualifikasi pendidikan pengelola program kesehatan lingkungan masih ada pengelola program yang berkualifikasi pendidikan tidak sesuai dengan standar yang ditetapkan.

"Saya pak D3 perawat tapi karena tidak ada yang kerja di program kesling, maka kapus ku mengSKkan sebagai pemegang program”. (An., 25 Juli 2015).

"Selama saya pegawai saya pegang program kesling saja, tidak ada yang lain mungkin na sesuai ki pendidikan $k u$ S 1 Kesmas Kesling”. (F, 24 Juli 2015).

Hal ini sesuai dengan penyataan informan kunci;

"Memang kalo dilihat dari kualifikasi pendidikann, seharus itu pendidikan minimal D.III Kesling pak yang pegang program, tapi masih ada itu yang dari perawat pegang program kesling, itu dimaklumi karena kurang $k i$ di sini tenaga kesling, ada beberapa orang yang PNS lainnya masih tenaga kontrak dan sukarela. (Yh, 21 Agustus 2015).

\section{Kebijakan}

Upaya program kesehatan lingkungan merupakan upaya kesehatan wajib yang harus ada di puskesmas sesuai Kepmenkes No. 128 Tahun 2004, selain itu ada program STBM, yang harus dilaksanakan oleh puskesmas, seperti penuturan informan:

"Kegiatan kesling tiap tahun ji selalu diprogramkan dan ada ji dalam POA nya puskesmas pak" (Hd, 26 Agustus 2015).

"Program STBM itu program nasional karena waktu pelatihan ki disampaikan ki itu, jadi puskesmas diwajibkan melaksanakan program tersebut" (Rc, 28 Agustus 2015). yang lain:

Hal ini diperkuat penuturan informan

"Program kesling itu masuk upaya kesehatan wajib dan itu kan sudah program nasional jadi kita harus ikuti itu, ada juga program STBM yang harus dilaksanakan, semua itu ditujukan untuk mencapai target SPM". (Tkd, 23 Juli 2015)

\section{Dana Operasional}

Dana operasional untuk pelaksanaan program kesehatan lingkungan berasal dari dana Bantuan Operasional Kesehatan (BOK) untuk 
puskesmas yang jumlahnya tergantung dari masing-masing puskesmas.

"Dana operasional memang ada tetapi kayaknya dana dari BOK itu karena ada ki di POA nya puskesmas tapi hanya untuk transport saja untuk berkegiatan" (F, 24 Juli 2015).

"Untuk kegiatan kesehatan lingkungan dana yang digunakan itu berasal dari BOK berupa transport kegiatan ji, dan kalo ada pertemuan kita pakai dana untuk konsumsi” (Sbh, 23 Juli 2015).

"Begini pak untuk program kesling itu khusus STBM itu ada dananya yang dibiayai oleh puskesmas sendiri, dan ada juga yang dari dinkes untuk kegiatan pemicuan" (Yh, 21 Agustus 2015).

\section{Kewenangan dan Tanggungjawab}

Kewenangan dalam penelitian ini adalah kekuasaan formal yang dimiliki oleh pelaksana program kesehatan lingkungan di tingkat puskesmas. Dengan wewenang mereka dapat melaksanakan program dan kegiatan sesuai dengan tupoksi yang tertuang dalam bentuk surat keputusan yang dikeluarkan oleh pimpinan, masih ada yang belum mempunyai legalitas tetapi sudah mempunyai kewenangan untuk melaksanakan program.

"Sudah satu tahun mi saya pegang program, saya yang buat laporan triwulan dan tahunan, bahkan diikutkan maka juga pelatihan di dinkes, tapi belum adapi SK ku untuk pengelola kesling (An. 25 Juli 2015).

Hal ini sesuai penuturan informan kunci "Jadi pemegang program kesling kami beri kewenangan untuk melaksanakan tugas berdasarkan SK dari kepala puskesmas dan telah saya arahan dan bimbingan terkait dengan tugas yang akan mereka laksanakan" (Tkd. 23 Juli 2015).

\section{Sarana dan Prasarana}

Pelaksanakan program kesling di puskesmas tentunya memerlukan sarana, hasil penelitian mengungkapkan bahwa ketersediaan sarana transportasi untuk mengakses daerah yang sulit dan jauh belum ada, beberapa puskesmas mempunyai sanitasi KIT, dan cetakan jamban.

“... klo kita mau melakukan kegiatan kadang mauki turun lapangan tapi daerahnya susah dijangkau dan tidak ada kendaraan operasional" (Wy. 23 Juli 2015).

"Setelah pemicuan kadang masyarakat minta alat untuk membuat jamban tetapi di puskesmas tidak ada cetakan jamban jadi saya menyarankan untu membeli saja kloset" (Md. 26 Agustus 2015).

Hal ini sesuai dengan pernyataan informan kunci, sebagai berikut:

"Pelaksanaan program untuk puskesmas memang kadang mau melaksanakan secara rutin tapi terkendala pada transportasi belum ada pi kendaraan operasionalnya”. (Yh, 21 Agustus 2015)

Program kegiatan dapat terlaksana apabila tersedia prasarana penunjang, salah satunya buku panduan. Pada umumnya puskesmas sudah memiliki panduan khususnya STBM, tetapi untuk kegiatan lain belum mempunyai buku panduan.

" Ada buku itu dikasikan ki sama orang dinkes tapi satu ji kegiatan, yang lainnya tidak ada pi yang saya punya” (Rc, 28 Agustus 2015).

Hal ini sejalan dengan pernyataan:

"Buku panduan itu biasanya di bagi pada waktu pelatihan, tapi kadang teman-teman juga tidak peduli dengan buku panduan itu, kadang ada lagi datang kesini untuk minta lagi, dan untuk kegiatan yang rutin memang dulu-dulu ji ada panduannya" (Yh, 21 Agustus 2015).

Komponen input program yang belum memadai adalah indikator sarana dan prasarana serta dana operasional kegiatan, sedangkan yang sudah memadai indikator SDM, kebijakan, kewenangan dan tanggung jawab.

\section{Proses Program STBM}

Indikator proses program STBM yang digunakan dalam penelitian ini mengajukan pada fungsi-fungsi manajemen. 


\section{Perencanaan}

Perencanaan kegiatan di puskesmas telah dilaksanakan diawali dengan lokakarya mini tingkat puskesmas, dari hasil tersebut diajukan untuk disusun jenis dan bentuk kegiatan yang dituangkan dalam POA. Semua puskesmas sudah penyusun POA untuk kegiatan satu tahun. Sebagaimana penuturan salah seorang informan yaitu;

"Begini pak, kalo kegiatan yang dilaksanakan memang harus ada di POA itu sesuai pedomannya BOK, tetapi untuk kegiatan yang masuk di POA harus ada datanya, misalnya data sasaran, (Rc, 23 Juli 2015).

“... klo program itu utamanya STBM itu memang sudah karena bagian merupakan program wajib di puskesmas” (Sp, 23 Juli 2015).

informan kunci:

Hal ini sesuai dengan keterangan

"Mengenai perencanaan kegiatan di puskesmas khususnya STBM itu diawali dengan penyusunan usulan kegiatan berdasarkan data yang ada kemudian mengajukan usulan itu dan membuat POA sesuai rencana yang biasanya dibahas dalam lokakarya mini”. (Yh, 21 Agustus 2015).

\section{Pengorganisasian}

Tahapan sebelum pelaksanaan kegiatan adalah pengoorganisasian, siapa yang bertanggung jawab dan personil yang terlibat di dalam kegiatan yang dituangkan dalam bentuk SK penanggung jawab kegiatan sesuai yang tercantum plan of action masing-masing puskesmas:

"Sebelum kita berkegiatan itu ada surat tugas nakasikan kepala puskesmas,siapasiapa yang turun ke lapangan" ( $N a, 23$ Juli 2015).

“...biasanya klo mauki ke desa melakukan penyuluhan itu di kasih ki surat tugas dari kapus, biasanya berdua ka dengan orang promkes" (St, 3 Agustus 2015).

Hal ini didukung oleh penuturan informan lainnya:
“ Setiap pemegang program di puskesmas itu saya buatkan semua. Karena data itu kita kirim ke kabupaten dan kabupaten meng SK kan kembali untuk semua puskesmas" (23 Juli 2015).

\section{Pelaksanaan}

Berdasarkan observasi dan wawancara terhadap informan, program STBM dilaksanakan dengan melibatkan lintas program dan lintas sektor, kegiatan yang dilaksanakan berupa penyuluhan dan pemicuan. Hasil penelitian ini diperkuat dengan penuturan salah seorang informan.

“... ya kalo kegiatan saya tidak bisa ka jalan sendiri, kadang orang promkes ikut dan petugas yang ada di desa, kemudian kalo di lapangan mi pasti saya berkoordinasi dengan kepala desa atau pak dusun di mana kegiatanku di laksanakan pak" (F, 24 juli 2015).

“... dalam melaksanakan kegiatan kan sudah dibuatkan surat tugas siapa-siapa yang terlibat kemudian sasaran tempat kegiatan. Biasanya juga sudah dihubungi pak desa sebelumnya tentang jadwal kegiatan"(Ad, 3 Agustus 2015).

Hal ini sejalan dengan keterangan informan :

"Kegiatan kesling itu kita melibat kan lintas program dan lintas sektor, karena pada waktu lokmin di hadiri juga lintas sektor sehingga mereka tau juga kalo program itu dibutuhkan partisipasinya" (Th, 24 Juli 2015).

\section{Pelaporan}

Setiap kegiatan pelaporan diharapkan masuk setiap bulan atau setiap selsesaai kegiatan dari pelaksana program ke Puskesmas dan Dinas Kesehatan Kabupaten Mamuju, namun tidak semua puskesmas melaporkan kegiatan tepat waktu. Hal tersebut menurut analisa peneliti disebabkan karena alat pendukung untuk pelaporan yang belum memadai, belum konsistensi antara POA yang telah disusun dengan jadwal kegiatan, sehingga laporan ke Dinas Kesehatan terlambat. Hal ini diungkap seperti penuturan informan.

“... disini kadang lambat ki buat laporan karena komputernya satu ji dan di pakai untuk semua program, jadi kita 
biasa antri dan kadang dibawa pulang ke rmh"(An, 23 Juli 2015).

"Setiap pemegang program wajib membuat laporan pertangngung jawaban kegiatan yang akan dilaporkan dalam loka karya mini puskesmas" (Tkd, 23 Juli 2015).

Hal ini sesuai dengan penuturan informan kunci bahwa:

"Laporan teman-teman dari puskesmas, ada juga yang rajin melaporkan tapi ada juga yang nanti disampaikan kalo laporannya belum masuk baru dikirim" (Yh. 21 Agustus 2015).

\section{Pemantauan atau Monitoring}

Pemantauan atau monitoring merupakan bagian dari fungsi manajemen. Monitoring akan memberikan informasi tentang status dan kecenderungan bahwa pengukuran dan evaluasi yang diselesaikan berulang dari waktu ke waktu. Penelitian ini mengungkapkan bahwa kegiatan yang telah dilaksanakan dipantau secara berkala berdasarkan kesepakatan masyarakat, setiap bulan dilakukan pemantauan terhadap kegiatan yang telah dilaksanakan dan dilaporkan pada saat pertemuan atau lokakarya mini. Hal ini sesuai dengan penuturan informan:

"Setelah dilakukan pemicuan kami akan turun kembali sesuai jadwal untuk melihat apakah ada masyarakat yang sudah membangun jamban atau tidak" (Ah, 28 Agustus 2015).

Hal ini sejalan dengan penuturan informan lainnya:

“... ya pak mengenai pemantauan atau monev itu petugas kami turun lagi ke lapangan setiap bulan apakah ada perubahan misalnya apakah sudah ada masyarakat yang buat jamban. Laporan seperti itu petugas kami melaporkan secara. tertulis hasil pemantauanya, apakah ada yang bertambah atau tidak dan di paparkan nanti di lokmin pak" (RB, 23 Juli 2015)

\section{Output Program STBM}

Output dari program STBM di tingkat puskesmas adalah meningkatkan cakupan upaya STBM terutama cakupan jamban keluarga. Hasil penelitian mendapatkan bahwa pada umumnya cakupan jamban keluarga masih dibawah target nasional, hal ini disebabkan oleh respon masyarakat yang masih kurang, dan menganggap itu belum menjadi kebutuhannya. Hal ini sesuai dengan penuturan informan:

“...pada saat kita berkegiatan pak mereka antusias mendengarkan materi penyuluhan, kita bermain dengan mereka pada saat pemicuan, tetapi selesai dan ditindaklanjuti belum ada pi yang buat jamban, katanya lagi pak saya kira dikasiki nanti bantuan buat jamban"(An., 23 Juli 2015).

"Kendala selama ini klo selesai pemicuan kita melihat kembali apakah perubahan atau tidak, ternyata masih banyak masyarakat yang belum mau berubah"(Nk, 4 Agustus 2015).

\section{Desa yang Melaksanakan STBM}

Desa yang melaksanakan STBM adalah suatu desa dikatakan telah melaksanakan STBM apabila telah ada intervensi melalui pemicuan di salah satu dusun dalam desa/kelurahan tersebut, ada masyarakat yang bertanggung jawab untuk melanjutkan aksi intervensi STBM seperti disebutkan pada poin pertama, baik individu (natural leader) atau pun bentuk kelompok masyarakat, dan sebagai respon dari aksi intervensi STBM, kelompok masyarakat menyusun suatu rencana aksi kegiatan dalam rangka mencapai komitmen perubahan perilaku pilar STBM, yang telah disepakati bersama. Berdasarkan hasil penelitian diungkapkan bahwa baru beberapa desa yang sudah melaksanakan STBM.

"Pelaksanan STBM di desa susah sekali karena masih banyak warga yang tidak tahu klo kesehatan itu penting khususnya STBM" (Dw, 23 Juli 2015).

Hal ini sesuai dengan pernyataan:

“...iya pak ini memang kendala terkait desa yang melaksanakan STBM, karena puskesmas melaksanakan kegiatan pemicuan dan Kabupaten juga melaksanakan, tapi frekuensinya sedikit disebabkan dana untuk kegiatan masih terbatas, jadi tiap puskesmas rata-rata 1 
- 2 desa saja belum semua desanya yang melaksanakan STBM" ( Yh, 21 Agustus 2015).

\section{Desa Stop BABs}

Cakupan desa Stop BABs yang ada di Kabupaten Mamuju, dari hasil penelitian mengungkapkan bahwa hanya 1 desa yang sudah Stop BABS dari 15 desa yang sudah melaksanakan program STBM, hal ini disebabkan masih rendahnya kesadaran masyarakat untuk membuat dan memanfaatkan jamban.

"Kegiatan pemicuan sudah dilaksanakan pak, cuma ya masyarakat kalo sdh mi di picu harapan ta. bisa mi membuat jamban yang sederhana saja sesuai kemampuannya, tetapi kadang-kadang berapa kali mi kita kunjungi belum dibuat-buat pak", ya begitu mi pak jadi mereka masih buang air besar sembarang tempat” (Sp, 23 Juli 2015).

Hal ini sesuai dengan penuturan informan:

"Stop BAB di Kabupaten Mamuju masih sangat rendah cakupannya selain karena biaya mahal serta masyarakat membutuhkan bantuan secara langsung” (Mc, 3 Agustus 2015).

\section{PEMBAHASAN}

\section{Input Program STBM} Sumber Daya Manusia

Manusia dalam hal ini merupakan ujung tombak dalam melaksanakan program STBM. Peran dan keberadaan mereka sangat menentukan keberhasilan pelaksanaan program di puskesmas. Oleh karena itu sangat dibutuhkan dukungan tenaga kesehatan yang terampil dan berkualitas. Dalam penelitian ini tenaga kesehatan yang bertugas sebagai pelaksana program di tingkat puskesmas adalah sebagian besar tenaga pendidikan tingkat D3 tetapi dalam status kepegawaian pada umumnya masih berstatus tenaga kontrak/sukarela disamping itu tugas pokok sebagai pelaksana program STBM juga melaksanakan tugas yang lainnya. Menurut Rahmawati (2007) bahwa SDM sangat penting untuk dikaji dalam rangka meningkatkan pelayanan kesehatan yang efektif dan efisien. Untuk itu diperlukan tenaga kesehatan yang sesuai dengan kualifikasi pendidikan sehingga dapat melaksanakan program dengan profesional. Pelatihan tentang program STBM diberikan agar petugas pelaksana program dapat menjalankan tugasnya secara profesional dengan hasil yang optimal. Pelatihan adalah investasi organisasi yang penting dalam sumber daya manusia. Pelatihan melibatkan segenap sumber daya manusia untu mendapatkan pengetahuan dan keterampilan pembelajaran sehingga mereka segera akan menggunakannya dalam pekerjaan (Juliani A, Sidik D, Rismayani, 2012). Hal ini sejalan dengan penelitian menyatakan bahwa pelatihan sangat penting untuk meningkatkan kemampuan dan keterampilan dan dengan demikian kinerja pegawai meningkat (Siriyei I, dan Wulandari RD, 2013).

\section{Kebijakan}

Tujuan dari pembangunan nasional di bidang kesehatan adalah meningkatkan kesadaran, kemamuan dan kemampuan hidup sehat bagi setiap orang agar terwujud masyarakat yang optimal melalui terciptanya masyarakat, bangsa dan negara yang ditandai oleh penduduknya yang hidup dengan perilaku dan lingkungan yang sehat, memiliki kemampuan untuk menjangkau pelayanan kesehatan yang bermutu, secara adil dan merata serta memiliki derajat kesehatan yang optimal. Program STBM merupakan program yang wajib dilaksanakan pada setiap pusat pelayanan kesehatan di masyarakat. Program ini dilaksanakan untuk meningkatkan akses dan pelayanan kesehatan msyarakat utamanya kegiatan promotif dan preventif untuk mewujudkan pelayanan kesehatan sesuai Standar Pelayanan Minimal (SPM) bidang kesehatan. Kebijakan (policy) adalah sebuah instrument pemerintah, bukan saja dalam arti government yang hanya menyangkut aparatur negara, melainkan pula governance yang menyentuh pengelola program publik. Sehingga dengan adanya kebijakan yang diberikan kepada pengelola program sehingga programprogram STBM tersebut dapat dijalankan dengan baik (Dasmar, Darmawansyah, Jafar N, 2013). Hal ini sejalan dengan penelitian, dimana kebijakan yang memadai yaitu kebijakan dana BOK tentang Petunjuk Teknis Bantuan Operasional Kesehatan dimana dana BOK diharapkan dapat meningkatkan akses dan pemerataan pelayanan kesehatan (Handayani L, Mulasari SA, Nurdianis N, 2008).

\section{Dana Operasional}


Dukungan pembiayaan adalah hal yang harus dipenuhi agar program tersebut bisa terlaksana dengan baik. Dalam penelitian ini, dana operasional yang digunakan di tingkat pelayanan puskesmas adalah dana yang bersumber dari Bantuan Operasional Kesehatan (BOK). BOK adalah bantuan dana dari pemerintah melalui Kementerian Kesehatan dalam membantu pemerintah Kabupaten/Kota melaksanakan pelayanan kesehatan sesuai Standar Pelayanan Minimal (SPM) bidang kesehatan menuju Millenium Development Goals (MDGs) dengan meningkatkan kinerja puskesmas dan jaringannya. Hal ini sesuai dengan hasil penelitian menyatakan bahwa dana mempunyai peranan yang sangat penting dalam melaksanakan program PMT Balita dengan sumber dana diperoleh dari APBD (Dodo D, Trisnantoro L, Riyarto S, 2012). Pembiayaan sangat dibutuhkan dalam pelaksanaan kegiatan, sehingga apabila terjadi keterlambatan pencairan dana maka kegiatan akan terhambat.

Penyebab keterlambatan pencairan dana BOK dan Jamkesmas ini adalah karena dua faktor diantaranya keterlambatan dari alokasi dari pemerintah pusat dan kemampuan dan kapasitas dari sumber daya manusia di puskesmas dalam membuat Plan of Action $(\mathrm{PoA})^{10}$. Ketidakpastian pembiayaan ini menyulitkan tenaga kesehatan yang ada di tingkat pelayanan dasar di kecamatan dan desa/posyandu. Tenaga kesehatan mengeluarkan biaya sendiri atau berhutang kepada pihak lain. Dalam kondisi ketidakpastian pembiayaan ini, sangat sulit untuk menjalankankegiatan rutin dan membuat inovasi di tingkat desa atau puskesmas. Akibat dari keterlambatan pencairan dana akan mengacaukan implementasi pelaksanaan program kesehatan dan menurunkan moral kerja dari pegawai (Wibowo, 2013).

\section{Kewenangan dan Tanggungjawab}

Kewenangan petugas pengelola program merupakan kekuasaan yang dimiliki namun kewenangan tersebut harus dipertanggungjawabkan kepada pimpinan organisasi. Kewenangan atau authority pada dasarnya merupakan kekuasaan formal atau terlegitimasi. Dalam sebuah organisasi, seseorang yang ditunjuk atau dipilih untuk memimpin suatu organisasi, bagian memiliki kewenangan atau kekuasaan yang terlegitimasi. Kewenangan dalam penelitian ini adalah kekuasaan formal yang dimiliki oleh pelaksana program STBM di tingkat puskesmas. Dengan wewenang mereka dapat melaksanakan program dan kegiatan sesuai dengan tupoksi yang tertuang dalam bentuk surat keputusan yang dikeluarkan oleh pimpinan. Kegiatan dan program dilaksanakan berdasarkan perencanaan yang telah disusun bersama dengan Kepala Puskesmas.

\section{Sarana dan Prasarana}

Sarana merupakan alat bantu untuk memperlancar dan mempermudah suatu pekerjaaan. Ketersediaan sarana dan prasarana dalam pelaksanaan program STBM belum memadai, beberapa puskesmas tidak mempunyai sanitari KIT, cetakan jamban dan kendaraan operasional bagi pengelola program. Buku panduan merupakan pedoman dasar dalam melaksanakan program STBM. Dalam buku tersebut dijelaskan secara terperinci terkait dengan kegiatan yang akan dilaksanakan agar memperoleh hasil yang maksimal.

Dalam penelitian ini masih banyak pengelola program STBM tingkat puskesmas yang tidak memiliki buku panduan pelaksanaan program sehingga mereka tidak memiliki pedoman dalam melaksanakan program. Tenaga pengelola program STBM puskesmas tidak berasal dari latar belakang ilmu kesehatan lingkungan akan mengalami kesulitan dalam melaksanakan program tersebut. Berdasarkan penelitian bahwa ada puskesmas yang tidak memiliki buku panduan karena petugas tersebut tidak memperoleh dari petugas program sebelumnya dan ada juga buku pedoman yang sudah hilang dan sudah tidak pernah lagi ada pembaharuan terhadap buku panduan sehingga jika ada petugas baru, maka tidak ada buku panduan yang dimiliki (Siriyei I, dan Wulandari RD, 2013).

\section{Proses Program STBM Perencanaan}

Perencanaan pada tingkat puskesmas adalah proses penyusunan rencana tahunan puskesmas untuk mengatasi masalah kesehatan di wilayah kerja puskesmas, langkah-langkah yang dilakukan dalam perencanaan adalah menyusun usulan kegiatan, mengajukan usulan kegiatan dan menyusun rencana pelaksanaan. Upaya kesehatan wajib khususnya program STBM di puskesmas pada penelitian ini pada dasarnya sudah melaksanakan sesuai ketentuan. Pemegang program menyusun usulan kegiatan, kemudian mengajukan pengusulan kegiatan 
pada lokakarya mini tingkat puskesmas dan menyusun rencana pelaksanaan kegiatan.

\section{Pengorganisasian}

Pengorganisasian adalah pengaturan sejumlah personel yang dimiliki untuk memungkin tercapainya suatu tujuan yang telah disepakati dengan jalan mengalokasikan masing-masing fungsi dan tanggung jawab, demikian halnya dalan penelitian ini untuk pelaksanaan kegiatan, semua tenaga yang terlibat dalam upaya program STBM diberikan fungsi dan tanggung jawab yang dituang dalam surat keputusan kepala puskesmas dan surat tugas pada saat kegiatan berlangsung. Pengorganisasian program BOK sudah memadai karena dalam Surat Keputusan sudah jelas diatur siapa mengerjakan apa (Handayani L, Mulasari SA, Nurdianis N, 2008). Kegiatan PMT Balita dikoordinir oleh petugas gizi puskesmas dan penetuan jenis makanannya disepakati bersama dengan kepala puskesmas dan petugas kesehatan puskesmas (Dodo D, Trisnantoro L, Riyarto S, 2012).

\section{Pelaksanaan}

Berdasarkan hasil wawancara dan telaah dokumen maka dapat disimpulkan bahwa pelaksanaan program STBM melibatkan lintas sektor dan lintas program yang ada di wilayah kerja puskesmas, adanya komitmen dari pimpinan dan pelaksana program. Pelaksanaan program klinik sanitasi puskesmas, belum terlaksana menurut yang diharapkan, karena masih kurangnya pemahaman petugas kesehatan yang terkait dengan kegiatan program klinik sanitasi untuk menjalankan standar prosedur operasional (SPO) klinik sanitasi, hal ini disebabkan karena petugas kesehatan yang ada di puskesmas belum pernah dilatih tentang program klinik sanitasi (Darsana IN, Mahayanan IMB, Patra IM, 2014).

\section{Pemantauan atau Monitoring}

Program STBM yang dilaksanakan ditingkat puskesmas yaitu penyuluhan kesehatan, pemicuan, pendataan keluarga yang melaksanakan program dan monitoring langsung ke lapangan untuk melihat sejauh mana kegiatan yang telah dilaksanakan. Fungsi penggerakan pelaksanakan adalah proses bimbingan ke staf agar mereka menjalankan tugas pokoknya sesuai dengan keterampilan yang dimiliki (Sari E, 2012).

\section{Output Program STBM}

Berdasarkan data dari informan dan telaah dokumen peneliti mendapatkan informasi tentang capaian program STBM di Kabupaten Mamuju meliputi jamban keluarga, desa yang melaksanakan STBM dan Stop BABs masih rendah.

\section{Jamban Keluarga}

Jamban Sehat adalah fasilitas pembuangan tinja yang efektif untuk memutus mata rantai penularan penyakit (Depkes RI, 2014). Berdasarkan hasil penelitain didapatkan data cakupan jamban keluarga yaitu cakupan tertinggi pada Puskesmas Binanga 83,64\% dan terendah pada Puskesmas Bambu 38,09\%, jika dibandingkan renstra Kemenkes 2010 - 2014 targetnya adalah $75 \%$, artinya masih ada puskesmas yang pencapaiannya masih dibawah target yang telah ditetapkan, hal ini sebabkan masih kurang frekuensi pemicuan dan masih rendahnya kesadaran masyarakat. Ada hubungan yang bermakna antara petugas kesehatan, pengetahuan dan sikap dengan kepemilikan jamban (Darsana IN, Mahayanan IMB, Patra IM, 2014). Penelitian yang menunjukkan bahwa pendidikan masyarakat mempengaruhi BAB pada tempatnya (Sholikhah S, 2014).

\section{Desa yang Melaksanakan STBM}

Desa STBM adalah desa/kelurahan intervensi pendekatan STBM dan dijadikan target antara untuk mencapai kondisi sanitasi total yang dibutuhkan dalam pencapaian lima pilar STBM. Dari hasil penelitian didapatkan 15 desa yang melaksanakan STBM, artinya cakupan desa STBM masih sangat rendah, hal ini disebabkan masih minimnya frekuensi pemicuan yang dilakukan oleh puskesmas dan dinas kesehatan, dana yang masih terbatas serta respon masyarakat yang masih rendah. Kurang berhasilnya program STBM dari proses pemicuan sampai pasca pemicuan karena masyarakat susah dikumpulkan sehingga proses monitoring dan pemantauan terhambat.

\section{Desa Stop BABs}

Desa Stop BABs adalah kondisi ketika setiap individu dalam komunitas atau desa tidak buang air besar sembarangan. Dari hasil penelitian didapatkan hanya satu yang menerapkan Stop BABs, hal ini disebabkan cakupan jamban yang masih rendah serta tingkat kesadaran masyarakat yang masih 
rendah. Hasil penelitian menyimpulkan bahwa pengetahuan, sikap dan tindakan termasuk kategori cukup tetapi belum memiliki jamban (Pranata A, Karno, Jayadi H, 2014).

\section{KESIMPULAN}

Kesimpulan ada beberapa komponen yang belum memadai yaitu komponen input pada indikator sarana dan prasarana serta dana operasional kegiatan. Komponen proses pada indikator pelaksanaan dan pemantauan. Komponen output pada semua indikator belum memenuhi target nasional yang ditetapkan.

\section{UCAPAN TERIMA KASIH}

Kepada Direktur Poltekkes Kemenkes Mamuju yang telah memberi kesempatan dan memberi dana penelitian melalui DIPA Poltekkes Mamuju Tahun 2015.

\section{DAFTAR PUSTAKA}

Depkes RI. (2014). Hasil riset kesehatan dasar. Jakarta.

Dinkes Provinsi Sulbar. (2013). Profil kesehatan Provinsi Sulawesi Barat. Mamuju.

Dinkes Kabupaten Mamuju. (2013). Profil kesehatan Kabupaten Mamuju. Mamuju.

Hadisaputro, Soeharyo. (2011). Epidemiologi Manajerial. Semarang: Badan Penerbit Universitas Diponegoro.

Arikunto. (2010). Evaluasi program pendidikan. Jakarta: Bumi Aksara.

Suharto E, Marjuki, Soeharto I. (2006). Kebijakan dan perencanaan sosial. Departemen Komunikasi dan Pengembangan Masyarakat, Fakultas Ekologi Manusia IPB dan Sekolah Pascasarjana IPB.

Dasmar, Darmawansyah, Jafar N. (2013). Studi Evaluasi Program Dana Bantuan Operasional Kesehatan di Kabupaten Luwu. Jurnal AKK; 2 (1): 1 - 7.

Handayani L, Mulasari SA, Nurdianis N. (2008). Evaluasi Program Pemberian Makanan Tambahan Anak Balita. Yogyakarta. Jurnal Manajemen Pelayanan Kesehatan; 11 (01): 21-6.

Dodo D, Trisnantoro L, Riyarto S. (2012). Analisis Pembiayaan Program Kesehatan
Ibu dan Anak Bersumber Pemerintah dengan Pendekatan Health Account. Universitas Gadjah Mada. Yogyakarta. Jurnal Kebijakan Kesehatan Indonesia; 01(01).

Wibowo. (2013). Manajemen Kinerja. Jakarta: Rajawali Pers Edisi 3Cetakan 7.

Juliani A, Sidik D, Rismayani. (2012). Evaluasi program imunisasi puskesmas di Kota Makassar. Jurnal Fakultas Kesehatan Masyarakat; Makassar.

Siriyei I, dan Wulandari RD. (2013). Faktor Determinan Rendahnya Pencapaian Cakupan Standar Pelayanan Minimal Bidang Kesehatan di Puskesmas. Surabaya; Jurnal Administras Kesehatan Indonesia: 1(3).

Dinkes Kabupaten Mamuju. (2014). Profil kesehatan Kabupaten Mamuju.

Sari E. (2012). Analisis Sumberdaya Organisasi dalam Pelaksanaan Program Klinik Sanitasi Puskesmas di Kabupaten Padang Pariaman. diambil dari http://repository. unand. ac. id/20416/.

Darsana IN, Mahayanan IMB, Patra IM. (2014). Faktor-faktor yang Berhubungan dengan Kepemilikan Jamban Keluarga di Desa Jehem Kec. Tembuku Kab. Bangli Tahun 2012. Jurnal Kesehatan Lingkungan: 04 (2); $124-133$.

Sholikhah S. (2014). Hubungan Pelaksanaan Program ODF dengan Perubahan Perilaku Masyarakat dalam Buang Air Besar di Luar Jamban di Desa Kemiri Kec. Malo Kab. Bojonegoro. Jurnal Surya: 13 (02); 84 - 90.

Agustina T, Budi IS, Faisya AF. (2014). Evaluasi Pelaksanaan Program Sanitasi Total Berbasis Masyarakat Pilar Pertama (Stop Babs) di Wilayah Kerja Puskesmas Pemulutan. Jurnal FKM Universitas Sriwijaya.www.akademik. unsri.ac.id/paper12/download

Pranata A, Karno, Jayadi H. (2014). Faktor yang mempengaruhi belum ODF di Desa Kebonsari wilayah kerja Puskesmas Gantrung Kab. Madiun. Jurnal Gema Kesehatan Lingkungan: Edisi khusus; 1 4. 